\title{
El referéndum autonómico Regional referendums in Spain
}

\author{
Daniel López Rubio \\ Universidad Carlos III de Madrid \\ dalopezr@der-pu.uc3m.es
}

Recibido / received: 30/01/2017

Aceptado / accepted: 27/02/2017

\section{DOI: https://doi.org/10.20318/eunomia.2017.3645}

\begin{abstract}
Resumen
La Constitución Española de 1978 consagró un sistema en el que prima de un modo muy intenso la democracia representativa. El constituyente fue muy restrictivo en la regulación del referéndum, como demuestra el hecho de que en más de treinta años tan solo se han convocado dos a nivel nacional. Uno de los principales debates abiertos en la doctrina constitucional española es el relativo a si las Comunidades Autónomas pueden, dentro de este marco constitucional, celebrar referendos en su propio ámbito territorial. Más allá del ruido político que rodea la cuestión, el presente artículo pretende razonar acerca de las vías que podrían llegar a utilizarse para este fin. Siendo conscientes de la íntima conexión del debate con el proceso soberanista catalán, se realiza también una reflexión acerca de la constitucionalidad de la eventual convocatoria de un referéndum de autodeterminación.
\end{abstract}

\section{Palabras clave}

Referéndum, democracia directa, reforma constitucional, participación ciudadana, consultas populares, referéndum autonómico, secesión, autodeterminación.

\begin{abstract}
The Spanish Constitution of 1978 established a system that strongly prioritizes the representative democracy. The constituent power drew up a restrictive regulation of the referendum, as evidenced by the experience: only two national referendums have been called for over 30 years. One of the most significant open debates in the Spanish legal doctrine concerns the possibility for autonomous regions to call regional referendums within the Spanish constitutional framework. Beyond the political noise that surrounds the issue, this paper aims to discuss ways to achieve this purpose. Bearing in mind the close connection between this debate and the Catalan separatism, we will also consider the constitutionality of an eventual call for a self-determination referendum.
\end{abstract}

\section{Keywords}

Referendum, direct democracy, constitutional reform, citizen participation, popular consultations, regional referendum, secession, self-determination.

SUMARIO. El modelo de democracia adoptado por la Constitución Española. 2. Modalidades de referéndum en la Constitución Española. 3. El referéndum autonómico. 3.1 La cuestión competencial. 3.2 Las vías posibles para instaurar un referéndum 
autonómico. 3.3 Referéndum de autodeterminación. 4. Conclusiones.

\section{El modelo de democracia adoptado por la Constitución Española}

Ya en su mismo Preámbulo, la Constitución Española de 1978 declaró la voluntad de la Nación española de "establecer una sociedad democrática avanzada". De esta forma, y a través de su artículo 1.1. España quedó configurada como Estado social y democrático de Derecho. Tras cuatro ominosas décadas de dictadura, el país lograba forjar su primera Constitución de consenso y recuperaba los valores democráticos.

El artículo 23 de la Constitución consagra uno de los elementos definitorios del proceso democrático: el derecho de sufragio. $Y$ lo hace queriendo abarcar en su ámbito de protección tanto los procesos electorales como los de índole referendaria. En efecto, queda reconocido a los ciudadanos "el derecho de participar en los asuntos públicos, directamente o por medio de representantes, libremente elegidos en elecciones periódicas por sufragio universal". El desarrollo de este precepto, en lo relativo a la participación directa de los ciudadanos, no fue especialmente intenso en el articulado constitucional. Referéndum e iniciativa legislativa popular, las únicas dos instituciones que, junto con el concejo abierto, son consideradas por el Tribunal Constitucional como expresión de la participación directa en los asuntos públicos consagrada en el artículo $23.1^{1}$, fueron objeto de una regulación restrictiva.

El proceso de restricción fue especialmente nítido en los debates constituyentes. Así, el Anteproyecto de Constitución ${ }^{2}$ preveía en su artículo $85^{3}$ dos modalidades de referéndum que acompañaban al relativo a decisiones políticas de especial trascendencia que hoy pervive: uno de ratificación de leyes aprobadas por las Cortes Generales, previo a su sanción, y otro para la derogación de leyes plenamente vigentes. En el caso del referéndum derogatorio, se admitía su activación popular a través de 750.000 electores $^{4}$. La potencia de fuego de la que se dotó en un primer momento a la institución referendaria fue intensamente rebajada en la Comisión de Asuntos Constitucionales del Congreso de los Diputados a partir de una enmienda planteada por el diputado Jordi Solé Tura, quien consideraba que la primigenia redacción del artículo suponía un grave riesgo de menoscabo de la soberanía del Parlamento ${ }^{5}$.

Se impuso, en términos de Aguiar (2000: 74), "la clara opción del constituyente español por consolidar un sistema de partidos fuerte como base imprescindible para la naciente democracia española". Se señala con frecuencia

\footnotetext{
1 STC 119/1995, FJ 3.

2 Publicado en el BOCG de 5 de enero de 1978.

${ }^{3}$ Art. 85 del Anteproyecto: 1. La aprobación de las leyes votadas por las Cortes generales y aún no sancionadas, las decisiones políticas de especial trascendencia y la derogación de las leyes en vigor, podrán ser sometidas a referéndum de todos los ciudadanos. 2. En los dos primeros supuestos del número anterior el referéndum será convocado por el Rey, a propuesta del Gobierno, a iniciativa de cualquiera de las Cámaras, o de tres asambleas de Territorios Autónomos. En el tercer supuesto, la iniciativa podrá proceder también de setecientos cincuenta mil electores. 3 . El plazo previsto en el artículo anterior, para la sanción real, se contará, en este supuesto, a partir de la publicación oficial del resultado del referéndum. 4 . El resultado del referéndum se impone a todos los ciudadanos y a todos los órganos del Estado. 5. Una ley orgánica regulará las condiciones del referéndum legislativo y del constitucional, así como la iniciativa popular a que se refiere el presente artículo y la establecida en el artículo 80.

4 De gran similitud con el artículo 75 de la Constitución Italiana de 1948: "Se celebrará referéndum popular para decidir sobre la derogación total o parcial de una ley o de un acto con fuerza de ley cuando lo soliciten quinientos mil electores o cinco consejos regionales".

${ }^{5}$ Diario de Sesiones del Congreso de los Diputados, 6 de junio de 1978, p. 2937.
} 
como motivo subyacente de esta posición el perverso uso que hiciera del instrumento plebiscitario el régimen franquista ${ }^{6}$. Sea como fuere, lo cierto es que el ordenamiento constitucional español configura un régimen principalmente representativo en el que las opciones de intervención directa de los ciudadanos son realmente escasas. Utilizando las palabras de Garrorena (1991: 148), "se trata, en definitiva, de apelar a una filosofía o concepción de la democracia que está -para decirlo apretadamente- más cerca de Montesquieu que de Rousseau, más próxima a la confianza en los representantes (...) que al ejercicio directo de la capacidad de participar".

La importancia limitada de las vías de democracia directa ha sido recalcada por el Tribunal Constitucional. Así, la STC 103/2008, que resolvió el celebérrimo asunto del "Plan Ibarretxe" y que aquí analizaremos con atención, expuso que "en tanto que instrumento de participación directa en los asuntos públicos, el referéndum es, junto con el instituto de la representación política, uno de los dos cauces de conformación y expresión de la voluntad general. Pero conviene destacar que se trata de un cauce especial o extraordinario, por oposición al ordinario o común de la representación política"7. Queda clara, pues, la preeminencia en nuestro actual modelo del sistema representativo de participación política.

\section{Modalidades de referéndum en la Constitución Española}

Antes de comentar el régimen de los diversos tipos de referendos que se contemplan en la Constitución, parece imprescindible definir la figura y distinguirla del concepto de "consultas populares". Para ello debemos acudir a la STC 103/2008, relativa a la consulta que el Parlamento Vasco convocó a través de la Ley 9/2008. En ella el Alto Tribunal subrayó que el referéndum es un tipo de consulta popular, siendo la relación entre ellos del tipo "especie-género". A través del referéndum, "no se recaba la opinión de cualquier colectivo sobre cualesquiera asuntos de interés público a través de cualesquiera procedimientos", sino que "su objeto se refiere estrictamente al parecer del cuerpo electoral, conformado y exteriorizado a través de un procedimiento electoral (...), siempre en relación con los asuntos públicos cuya gestión, directa o indirecta, mediante el ejercicio del poder político por parte de los ciudadanos constituye el objeto del derecho fundamental reconocido por la Constitución en el artículo 23"8. En síntesis, para poder saber si estamos ante un referéndum, debemos atender al sujeto consultado, de modo que, si coincide con el cuerpo electoral, y su canal de expresión es el procedimiento electoral, estaremos ante una consulta referendaria ${ }^{9}$.

\footnotetext{
6 Martín Nuñez (2012: 98) subraya que "el constituyente de 1978, receloso de las prácticas de legitimación plebiscitaria del régimen franquista, apuesta decididamente por fortalecer el protagonismo de los partidos políticos en el proceso de consolidación de la democracia constitucional española y se muestra reacio a admitir la irrupción en la vida política de pronunciamientos populares que pudiesen escapar al control de los representantes políticos". En los mismos términos se expresa Cuesta López (2008: 89). Señala, no obstante, Castellà (2016: 241) que en el debate "sobresalieron los argumentos estructurales o de modelo de democracia". Así, el autor apunta que "en las intervenciones de los portavoces parlamentarios predominan argumentos de carácter abstracto, con referencia a teóricos de la representación política o de la democracia (Burke, Rousseau, Schmitt), a la historia antigua y a algunas experiencias comparadas contemporáneas". Vírgala (2013: 19) también cuestiona el peso del argumento, indicando que "ni su utilización fue lo que mantuvo al régimen franquista en el poder ni tampoco fue un mecanismo utilizado de forma continuada (hay que recordar que Franco sólo convocó dos referenda: 1947 Ley de sucesión; 1966 LOE)".

7 STC 103/2008 FJ 2.

8 Ibídem, FJ 2.

${ }^{9}$ Carrasco Durán (2013: 16) considera necesaria la singularización del referéndum entre los demás tipos de consultas pues, dice, "resulta evidente la existencia de modalidades de consulta popular que
} 
Procedamos, pues, a realizar una somera explicación de las diferentes modalidades de referéndum que aparecen en nuestro texto constitucional. Distinguiremos entre referendos normativos y no normativos, esto es, en función de si van ligados o no a la aprobación de un texto legal.

Comenzando por los primeros, debemos destacar la figura del referéndum inserto en el proceso de reforma constitucional, llamado simplemente "referéndum constitucional". Recordemos que existen dos vías distintas para operar una reforma, empleándose una u otra en función de a qué parte de la Constitución afecte. El procedimiento más agravado, previsto para la revisión total de la Constitución, o para una parcial que afecte al Título preliminar, al Capítulo segundo, Sección primera, del Título primero, o al Título segundo, exige la ratificación final por el pueblo en referéndum ${ }^{10}$. Por consiguiente, la consulta tiene aquí un carácter preceptivo y vinculante. Para el resto de reformas constitucionales el referéndum es meramente potestativo, celebrándose únicamente si así lo solicitan una décima parte de los miembros de cualquiera de las Cámaras. La principal razón para la previsión de este mecanismo en la reforma constitucional parece ser, como apunta Aguiar (2000: 79), la protección de las minorías. Pese a que el bajo porcentaje exigido para solicitar la convocatoria de referéndum en el procedimiento ordinario pueda hacer pensar que éste se dará como paso obligado en cualquier tipo de reforma, lo cierto es que, en la práctica electoral española, como puede observarse en la siguiente tabla ${ }^{11}$, pocos grupos parlamentarios han contado por sí solos con tal cifra de miembros. Ello obligaría a lograr el entendimiento de parlamentarios pertenecientes a grupos diferentes.

\section{TABLA: NÚMERO DE GRUPOS PARLAMENTARIOS QUE ALCANZAN EL REQUISITO DEL 10\% EN CADA LEGISLATURA}

\begin{tabular}{|c|c|c|}
\hline Legislatura & $\begin{array}{c}\text { Congreso de los } \\
\text { Diputados }\end{array}$ & Senado \\
\hline$I$ (1979-1982) & 2 (GPC y GPS) & 2 (GPUCD y GPS) \\
\hline II (1982-1986) & 2 (GPS y GPP) & 2 (GPS y GPP) \\
\hline III (1986-1989) & 2 (GPS y GPCP) & $2-3^{*}$ (GPS y GPCP) \\
\hline$I V(1989-1993)$ & 2 (GPS y GPP) & 2 (GPS y GPP) \\
\hline$V(1993-1996)$ & 2 (GPS y GPP) & 2 (GPP y GPS) \\
\hline$V I(1996-2000)$ & 2 (GPP y GPS) & 2 (GPP y GPS) \\
\hline$V I I(2000-2004)$ & 2 (GPP y GPS) & 2 (GPP y GPS) \\
\hline$V I I I ~(2004-2008)$ & 2 (GPS y GPP) & 2 (GPP y GPS) \\
\hline
\end{tabular}

no se articulan a través de una votación y que, por lo tanto, son distintas al referéndum. Entre estas se encuentran las encuestas, audiencias públicas y foros de participación citados expresamente en algunos Estatutos de Autonomía de nueva generación".

10 Un estudio pormenorizado de este complejo proceso se encuentra en García-Escudero Márquez (2008).

${ }^{11}$ Elaboración propia a partir de datos oficiales extraídos de las páginas web del Congreso de los Diputados (www.congreso.es) y del Senado (www.senado.es). 


\begin{tabular}{|c|c|c|}
\hline$I X(2008-2011)$ & 2 (GPS y GPP) & 2 (GPP y GPS) \\
\hline$X(2011-2015)$ & 2 (GPP y GPS) & 2 (GPP y GPS) \\
\hline$X I(2016-2016)$ & $\begin{array}{c}4(G P P, G P S, G P P-E C P- \\
E M, G P C)\end{array}$ & 2 (GPP y GPS) \\
\hline$X I I(2016-)$ & $\begin{array}{c}4 \text { (GPP, GPS, GPP-ECP- } \\
E M, G P C)\end{array}$ & 2 (GPP y GPS) \\
\hline
\end{tabular}
requerida.

*Durante los años 1987 y 1988, el grupo mixto alcanzaba también la cifra

Otro referéndum de tipo normativo previsto en la Constitución es el contemplado para la aprobación de los Estatutos de las Comunidades que accedieran a la autonomía siguiendo el procedimiento del artículo 151.1 CE. Recordemos que nuestro texto jurídico supremo contempla dos vías de acceso a la autonomía. Una primera vía, de carácter ordinario, permitía asumir las competencias previstas en el artículo $148.1 \mathrm{CE}^{12}$. La segunda, que según el citado artículo 151.1 CE exige que la iniciativa autonómica sea ratificada mediante referéndum por el voto afirmativo de la mayoría de los electores de cada provincia (y de la que se exime a aquellos territorios que en el pasado hubieran plebiscitado afirmativamente proyectos de Estatuto de Autonomía, según la Disposición Transitoria $2^{\mathrm{a}} \mathrm{CE}$ ), permitía asumir cualquier competencia, con el único límite de las reservadas exclusivamente al Estado por el artículo 149.1 CE. Pues bien, como decimos, cuando una Comunidad utilice el iter preferente, la Constitución le exige que la aprobación de su Estatuto cuente con la ratificación del pueblo de cada una de las provincias que comprenden su territorio a través de referéndum. Existen, a su vez, dos posibilidades aquí. En la primera, una Asamblea de Diputados y Senadores han de aprobar un proyecto de Estatuto, que remitirá a la Comisión Constitucional del Congreso. Se discutirá en su sede junto con una delegación de aquella Asamblea y, en caso de que exista acuerdo, el texto resultante se someterá a referéndum en las provincias correspondientes. Si el cuerpo electoral de cada una de ellas lo aprobara, el proyecto se elevaría a las Cortes Generales para su definitiva ratificación. La segunda posibilidad está prevista para el caso en que la delegación de la Asamblea citada y la Comisión Constitucional no lleguen a un acuerdo. En este supuesto el proyecto se tramitará como proyecto de ley en las Cortes, siendo el texto generado sometido a referéndum. En caso de superarse, solo restaría su promulgación.

El último de los referendos normativos lo encontramos en el artículo 152.2 $\mathrm{CE}$, que establece la necesidad de referéndum para realizar una reforma de los Estatutos aprobados en seguimiento de la vía preferente. Es preciso en este punto señalar que, aunque la Constitución sólo impone el referéndum para la reforma de tales Estatutos, algunas Comunidades han optado por introducirlo en sus respectivas normas básicas, y ello en virtud del artículo 147.3 CE $^{13}$ ("La reforma de los Estatutos se ajustará al procedimiento establecido en los mismos y requerirá, en todo caso, la aprobación por las Cortes Generales, mediante ley orgánica"), que parece otorgar cierta libertad a la hora de configurar el proceso de reforma. De este

\footnotetext{
12 Una vez transcurridos cinco años, el artículo 148.2 CE permitía a estas Comunidades Autónomas aumentar su número de competencias a través de reforma estatutaria, y siempre bajo el respeto del límite de competencias exclusivas delimitado por el artículo 149 CE.

${ }^{13}$ La STC 31/2010, en su FJ 147, expone que la posibilidad de que las Comunidades que accedieron a la autonomía por la vía lenta instauren referendos de ratificación de la reforma de sus Estatutos es perfectamente constitucional, a la luz del "amplio margen de configuración" que sobre este particular les otorga el artículo 147.3 CE.
} 
modo, el Estatuto de Autonomía de Aragón (artículo 115.7), y el de Extremadura (artículo 91.2) han contemplado la posibilidad de celebrar un referéndum para ratificar la decisión final, siempre que lo solicite una mayoría cualificada de sus Parlamentos. El Estatuto de la Comunidad Valenciana (artículo 81.5) también ha contemplado un referéndum de ratificación, aunque éste resulta de obligada convocatoria ${ }^{14}$. Nos encontraríamos ante un supuesto de referéndum no expresamente previsto en la Constitución y que, sin embargo, no ha merecido duda de inconstitucionalidad alguna.

En segundo lugar, comentaremos los referendos de tipo no normativo. Inicialmente, hemos de hacer referencia al referéndum del artículo 92 de la Constitución. Se trata de una consulta que puede proponer el Presidente del Gobierno para cuestiones políticas de especial trascendencia. El objeto de la consulta, como vemos, es profundamente indeterminado. Ahora bien, siguiendo a Rodríguez Zapatero (1986, p. 1162), del tenor literal del precepto sí parece deducirse que las decisiones políticas no podrán ser leyes aprobadas y no sancionadas, ni la abrogación de leyes en vigor ${ }^{15}$. Debe ser autorizado por el Congreso de los Diputados, y su convocatoria formal corresponde al Rey. El propio artículo 92 establece que será una ley orgánica la que regule las condiciones y el procedimiento no sólo de esta modalidad de referéndum, sino de todas las previstas en la Constitución. Estamos ante un referéndum meramente consultivo, según prevé el artículo que lo regula. Ahora bien, la ausencia de efectos jurídicamente vinculantes no es óbice para poder señalar, como hace Alzaga (1980: 587), que si el pueblo se decanta claramente a favor de una determinada posición, no es probable, desde la óptica del realismo político, que los poderes públicos decidan ir en contra de la misma. Como ya se apuntó, el Anteproyecto de Constitución preveía un artículo 92 (en ese momento era el 85) mucho más completo. Y ello porque incluía las dos versiones antedichas de referéndum. La previsión original de estas dos modalidades legislativas explica la situación del artículo en el Capítulo II, dedicado a la elaboración de las leyes, del Título III, de las Cortes Generales. Tras los debates a los que supra hice referencia, el legislador constituyente redujo al mínimo las modalidades de referéndum, quedando solo en pie el consultivo para cuestiones políticas de gran importancia.

También podemos hablar de referéndum de carácter no normativo si acudimos al artículo 151.1 de la Constitución. Recordemos que en él se contempla la necesidad de superar un referéndum para poder ejercitar el acceso a la autonomía por la vía preferente.

El último de los referendos no normativos aparece en la Disposición Transitoria Cuarta de la Constitución, que prevé la necesidad de que una iniciativa autonómica que pretenda incorporar Navarra al País Vasco supere un referéndum por mayoría de los votos válidos emitidos.

Siguiendo el mandato establecido por el artículo 92.3 de la Constitución, las diversas modalidades de referéndum previstas en ella, que hemos ido enunciando, encuentran el desarrollo de su regulación en la Ley Orgánica 2/1980, de 18 de enero.

\footnotetext{
14 Salvo que la reforma solo implique ampliación competencial.

15 Requejo (2014: 264) coincide en la imposibilidad de que el objeto de la consulta sea una norma, pero considera que ello no es obstáculo para que, una vez celebrado el referéndum, se termine por plasmar su resultado en una ley.
} 


\section{El referéndum autonómico}

\subsection{La cuestión competencial}

A lo largo de los últimos años se ha desarrollado un interesante debate en torno a la posibilidad de que las Comunidades Autónomas puedan celebrar referendos distintos a los expresamente contemplados en la Constitución. Paralelamente, ha surgido controversia respecto de qué competencias pueden ostentar las mismas en la materia de consultas populares a celebrar por vía de referéndum, e incluso respecto de la posibilidad de que, sin ostentar competencias expresas, quepa la posibilidad de convocar referendos autonómicos.

Antes de comenzar con los principales exponentes de este debate, debemos apuntar dos elementos básicos a tener en cuenta en todo momento como marco para el mismo. En primer lugar, y como ya comentamos previamente, el artículo 92.3 de la Constitución exige que sea una ley orgánica la que regule las condiciones y el procedimiento de las diversas modalidades de referéndum previstas en la Constitución. En segundo lugar, el artículo 149.1.32 reserva al Estado competencia exclusiva para autorizar la convocatoria de consultas populares por vía de referéndum. Como digo, deberemos tener presentes ambos elementos a la hora de analizar la controversia en cuestión.

\subsubsection{Principales hitos en el debate}

El primero de los hitos en el seno de este debate aconteció en el año 2008. El entonces Lehendakari Juan José Ibarretxe planteó ante el Parlamento Vasco un texto legal que permitía celebrar una consulta en el País Vasco para obtener la opinión de sus ciudadanos en torno a la idea de abrir negociaciones con el Estado para alcanzar una nueva relación entre la Comunidad Autónoma y aquél. El Parlamento autonómico aceptó la iniciativa, aprobando la Ley 9/2008, de 27 de junio, cuya exposición de motivos establecía que su objeto era el de "recabar la opinión de los ciudadanos y ciudadanas vascas con derecho de sufragio activo sobre la apertura de un proceso de negociación para alcanzar la paz y la normalización política". Según la misma, al no ser una consulta jurídicamente vinculante, ni un referéndum, no le resultaba aplicable la Ley Orgánica 2/1980, ni la necesidad de autorización estatal contemplada en el artículo 149.1.32 de la Constitución.

El Gobierno de la Nación decidió plantear recurso de inconstitucionalidad contra la Ley 9/2008. Se hizo necesario, pues, que el Tribunal Constitucional asentara las diferencias entre referéndum y otras consultas populares y decidiera en cuál de las dos categorías encajaba la figura planteada por el Parlamento Vasco, para aclarar si la autorización del Estado era o no precisa. El fundamento jurídico $2^{\circ}$ de la STC 103/2008 estableció de manera contundente la delimitación. Así, como expusimos, estaremos ante un referéndum cuando el sujeto consultado sea el cuerpo electoral y el procedimiento adoptado para su expresión sea el electoral.

En el caso concreto, el Tribunal constató que la Ley llamaba a consultar a "los ciudadanos y ciudadanas del País Vasco con derecho de sufragio", es decir, al cuerpo electoral vasco, y además lo hacía remitiéndose a la Ley reguladora de las elecciones en tal Comunidad. La conclusión fue sencilla: la consulta era un referéndum, y requería la autorización estatal contemplada en el artículo 149.1.32 de la Constitución. No contando con ella, el Tribunal declara su nulidad. Es cierto que las razones a través de las cuales se materializó tal declaración de 
inconstitucionalidad fueron algunas más, pero en ellas incidiremos más adelante.

Imperiosa resulta la necesidad de subrayar, dentro de este primer hito, que el País Vasco nunca ha asumido competencias en materia de consultas populares por vía de referéndum. Una de las razones por las que la Ley 9/2008 se impugnó fue precisamente ésta, la ausencia de apoyo del texto en un título competencial expreso. El Gobierno vasco argumentó que la potestad de la Comunidad para convocar referendos era intrínseca al principio democrático y a la capacidad de autoorganizar sus propias instituciones de Gobierno. El Tribunal Constitucional no aceptó esta argumentación, dejando claro "que no cabe en nuestro ordenamiento constitucional, en materia de referéndum, ninguna competencia implícita". Y ello, dijo, por entrar en colisión con competencias expresas que sí posee el Estado, como la derivada del artículo 149.1.32 de la Constitución.

El segundo de los hitos a comentar es el relativo al Estatuto de Cataluña aprobado en 2006. Éste presenta un artículo 122 que atribuye a la Generalitat "la competencia exclusiva para el establecimiento del régimen jurídico, las modalidades, el procedimiento, la realización, y la convocatoria por la propia Generalitat o por lo entes locales, en el ámbito de sus competencias, de encuestas, audiencias públicas, foros de participación y cualquier otro instrumento de consulta popular, con excepción de lo previsto en el artículo 149.1.32 de la Constitución". El Tribunal Constitucional entendió, en su sentencia 31/2010, que el precepto era plenamente constitucional, siempre que se interpretara en el sentido de que "cualquier otro instrumento de consulta popular" no incluye el referéndum. Ello porque, según el Tribunal, al Estado corresponde no sólo la autorización de la convocatoria de consultas populares por vía de referéndum, sino la entera disciplina de la institución. El Alto Tribunal, para llegar a esta conclusión, parte de la idea de que "la Ley Orgánica 2/1980, sobre regulación de las diversas modalidades de referéndum, es la llamada por el artículo 92.3 para regular las condiciones y procedimiento de las distintas modalidades de referéndum previstas en la Constitución, y además es la única constitucionalmente adecuada para el cumplimiento de otra reserva, añadida a la competencial del artículo 149.1.32 CE: la genérica del artículo $81 \mathrm{CE}$ para el desarrollo de los derechos fundamentales, en este caso el derecho de participación política reconocido en el artículo 23 CE". En conclusión, el Tribunal emprende una interpretación especialmente restrictiva del artículo 122 EAC, afirmando que la entera disciplina de la institución referendaria corresponde al Estado. Es discutible si, a pesar de la potencia del enunciado, cabría espacio para algún tipo de actuación normativa de desarrollo por parte de las Comunidades Autónomas.

Resulta difícil compartir los argumentos ofrecidos en esta sentencia por el Tribunal Constitucional. En primer lugar, escaso sentido tiene aquí la apelación a la Ley Orgánica 2/1980. La Constitución encomienda a esta ley la regulación de aquellas modalidades de referéndum previstas en ella. Pues bien, aquí se está tratando un tipo de referéndum desconocido en el texto supremo, esto es, un referéndum de ámbito autonómico y diferente a aquellos previstos para la aprobación o reforma de los Estatutos de Autonomía ${ }^{16}$. En segundo lugar, no parece acertado extraer del artículo 149.1.32 CE, limitado a reservar al Estado la autorización de la convocatoria de referendos, conclusiones relativas al reparto de

\footnotetext{
16 Dada la referencia que realiza el artículo 92.3 CE a "las modalidades de referéndum previstas en esta Constitución", entiende Aguado (2011, p. 548) que "nada impediría, teóricamente, de acuerdo con esta literalidad, que pudiesen existir dos leyes orgánicas distintas reguladoras de referéndums, una para los previstos en la Constitución y otra para los demás". De hecho, recordemos que la Ley Orgánica 2/1980 no regula de un modo directo la figura de las consultas municipales, no previstas en la Constitución, sino que se remite a través de su Disposición Adicional a la legislación de régimen local.
} 
competencias normativas sobre el instituto en cuestión. Finalmente, poco peso tiene la apelación a que el desarrollo de los derechos fundamentales debe realizarse por ley orgánica. Resulta evidente que, pese a la corrección del enunciado, las Comunidades Autónomas poseen capacidad para desarrollar la normativa estatal en materia de derechos fundamentales ${ }^{17}$. En resumen, la categórica afirmación del Tribunal no descansa en sólidas premisas. La posibilidad de que las Comunidades Autónomas actúen en esta materia, siempre desde el respeto a una normativa básica estatal y a la necesidad de previa autorización estatal de las convocatorias, resulta mucho más razonable.

\subsubsection{Comunidades Autónomas con competencias en la materia: su interpretación a la luz de la jurisprudencia.}

Los Estatutos de las Comunidades Autónomas de Baleares, Castilla y León, La Rioja, Canarias, Asturias y Murcia contienen una previsión estatutaria (Artículos 31.10 EABal; 71.15 EACL; 9.7 EALR; 32.5 EACan; 11.11 EAAs; 11.8 EAMu) que les otorga competencia de desarrollo legislativo y ejecución en: "Sistema de consultas populares en el ámbito de [la Comunidad Autónoma de que se trate], de conformidad con lo que disponga la Ley a que se refiere el artículo 92.3 de la Constitución y demás leyes del Estado, correspondiendo a éste la autorización de su convocatoria". Una interpretación estricta de las directrices asentadas por la STC $31 / 2010$, nos llevaría a entender que la competencia se extiende únicamente a consultas de carácter no referendario (que no requerirían autorización previa), sin que quepa extensión alguna a la figura del referéndum, sobre la que el Estado se reserva la facultad de regular su entera disciplina. En la materia de consultas populares que no constituyan referéndum, las Comunidades Autónomas deberán respetar, en todo caso, la legislación básica que dicte el Estado en el ámbito de las Administraciones Públicas (artículo 149.1.18 de la Constitución), como expuso la misma sentencia del Tribunal Constitucional.

Por su parte, el Estatuto de la Comunidad Valenciana, en su artículo 28.5, dispone que "El President de La Generalitat podrá proponer, de acuerdo con lo que determine la legislación del Estado, la celebración de consultas populares en el ámbito de la Comunitat Valenciana, sobre cuestiones de interés general en materias autonómicas o locales". Habríamos de entender, una vez más, que estamos ante consultas no cualificadas como referéndum, y será preciso igualmente respetar la competencia exclusiva del Estado en materia de bases de las Administraciones Públicas.

Estas conclusiones, a priori lógicas a través de un entendimiento preciso de la doctrina asentada en la STC 31/2010, han quedado de algún modo matizadas por el propio Tribunal a través de la STC 137/2015, en la que se declaró la inconstitucionalidad de un decreto del gobierno autonómico de Canarias por el que se pretendía regular unas consultas esencialmente referendarias. En este pronunciamiento el Tribunal expuso que las Comunidades Autónomas sí pueden asumir competencias sobre "algún género de intervención en la ejecución o, incluso, en el complemento normativo de los preceptos estatales que disciplinen, en los términos señalados, unas u otras figuras de referéndum". Pese a la imprecisión con

\footnotetext{
${ }^{17}$ Como apunta Aguiar (Manuscrito de próxima publicación: 21), de gran interés al respecto resulta el caso de los procesos electorales: "(...) el hecho de que el régimen electoral general esté reservado a la ley orgánica por ser desarrollo del derecho de participación y por estar explícitamente contemplado en el artículo 81.1 CE (que comprende elementos tan relevantes para la celebración de las elecciones parlamentarias autonómicas como las que se enumeran en la Disposición Adicional $1^{\text {a }} .2$ de la LOREG) [tampoco] impide al legislador autonómico complementar la regulación autonómica de las elecciones".
} 
que se introduce esta ligera apertura, parecería habilitación suficiente para una intervención normativa de desarrollo de las mencionadas Comunidades Autónomas.

Los Estatutos de Andalucía, Aragón y Extremadura ${ }^{18}$ otorgan a las mismas competencias en materia de consultas populares, pero sus tenores literales excluyen expresamente el referéndum, sin que quepa, por tanto, comentario adicional alguno.

Por su parte, Galicia, Cantabria, Castilla-La Mancha, Madrid y Navarra, al igual que ocurre con el País Vasco, no presentan referencia alguna en sus Estatutos a la materia de consultas populares.

\subsection{Las vías posibles para instaurar un referéndum autonómico}

De lo dicho hasta ahora podemos extraer dos conclusiones fundamentales. La primera es que no cabe esgrimir potestades implícitas ligadas al principio democrático y a la capacidad de autoorganización institucional para convocar referendos de ámbito autonómico. Y la segunda supone que el Estado se reserva competencia para regular la entera disciplina de la institución referendaria, sin que sea posible asumir por parte de las Comunidades competencias al respecto más allá de un mero desarrollo (de contornos indefinidos) de la normativa estatal.

Siendo éstas las coordenadas de juego, podemos reflexionar acerca de qué opciones existen para que una Comunidad Autónoma pueda plantear un referéndum a sus ciudadanos, distinto a los ya expresamente previstos en la Constitución.

\subsubsection{La reforma constitucional}

Una primera gran vía sería la reforma constitucional. Incorporar al texto jurídico fundamental la posibilidad de que las Comunidades puedan celebrar referendos. Ahora bien, el objeto de esas consultas, ¿podría ser cualquiera? ¿Incluida la autodeterminación de un territorio? Existen voces contrarias a esta posibilidad. Aragón (1989: 63), por ejemplo, entiende que "ni hay Estado, ni Constitución, ni ordenamiento, si hay derecho de secesión; simplemente son entidades inconciliables". En la misma línea discurre el pensamiento de Tajadura (2009: 383), quien sostiene que en caso de modificarse la Constitución para suprimir o sustituir el artículo 1.2 por otro que no salvaguardara la unidad de la soberanía del pueblo español, ya no estaríamos ante "la misma Constitución reformada, sino ante otra Constitución distinta". No encuentra sin embargo reparos a esta vía, que defiende con intensidad, Aláez Corral (2015). No es este el lugar para realizar una profunda reflexión sobre la cuestión, pero sí pueden destacarse dos elementos de interés: primero, el hecho de que la jurisprudencia constitucional ha reiterado la inexistencia

\footnotetext{
18 Artículo 78 EAAnd: "Corresponde a la Junta de Andalucía la competencia exclusiva para el establecimiento del régimen jurídico, las modalidades, el procedimiento, la realización y la convocatoria por ella misma o por los entes locales en el ámbito de sus competencias de encuestas, audiencias públicas, foros de participación y cualquier otro instrumento de consulta popular, con la excepción del referéndum".

Artículo 71.27 EAAr: "Corresponde a la Comunidad Autónoma la competencia exclusiva en las siguientes materias: $27 .^{a}$ Consultas populares, que, en todo caso, comprende el establecimiento del régimen jurídico, las modalidades, el procedimiento, la realización y la convocatoria por la Comunidad Autónoma o por los entes locales en el ámbito de sus competencias de encuestas, audiencias públicas, foros de participación y cualquier otro instrumento de consulta popular, con excepción de la regulación del referéndum y de lo previsto en el artículo 149.1.32. ' de la Constitución".

Artículo 9.1.50 EAEx: "La Comunidad Autónoma de Extremadura tiene competencia exclusiva sobre las siguientes materias: 50. Régimen y convocatoria de consultas populares no vinculantes diferentes al referéndum".
} 
de límites materiales al poder de reforma constitucional ${ }^{19}$; y segundo, lo pacífico que sería el asunto si la previsión constitucional decretara que el ámbito dentro del cual pueden las Comunidades Autónomas convocar referendos es estrictamente el de sus competencias.

\subsubsection{Métodos legislativos}

Cabe plantearse, no obstante, la posibilidad de celebrar este tipo de referendos autonómicos sin necesidad de una previa reforma constitucional que los contemplase. A este respecto, es oportuno señalar que los hechos apuntan hacia la existencia de consultas referendarias no expresamente previstas en la Constitución, y cuya presencia ha sido plenamente pacífica. Así, contamos con los referendos para la agregación/segregación a una Comunidad Autónoma de municipios enclavados íntegramente en su territorio (artículo $8^{\circ}$ del Estatuto del País Vasco, y Disposición Transitoria $3^{\mathrm{a}}$ del Estatuto de Castilla y León, respectivamente); también se han previsto referendos de reforma estatutaria para Comunidades (Valencia, Aragón y Extremadura) cuyo Estatuto fue aprobado por la vía ordinaria, basándose en la libertad regulatoria del artículo 147.3 de la Constitución; y finalmente se han contemplado consultas referendarias a nivel local, tanto en la Ley Orgánica reguladora de las diversas modalidades de referéndum (en concreto en su Disposición Adicional ${ }^{20}$ ), como en la Ley Reguladora de las Bases del Régimen Local (artículo $71^{21}$ ). La existencia no controvertida de estos referendos, pese a su no inclusión expresa en la Constitución, parece un poderoso argumento en contra de la obligatoriedad de emprender una reforma constitucional.

Dentro de los argumentos que parten de la ausencia de necesidad de reformar la Constitución para celebrar un referéndum autonómico, encontramos el siguiente: el uso del referéndum consultivo sobre decisiones políticas de especial trascendencia del artículo 92 de la Constitución, y cuya regulación se desarrolla en la Ley Orgánica 2/1980. Habríamos de reflexionar acerca de si cabe emplear esta figura para preguntar únicamente a una parte del cuerpo electoral. Aguiar (2000: 87) cree que "el artículo 92 en ningún punto consagra de modo explícito que el ámbito de estas consultas populares deba ser todo el territorio nacional". Por su parte, Castellà (2013: 202) entiende que "no se puede obviar una objeción derivada del propio texto constitucional, el cual se refiere a que tales decisiones políticas podrán ser sometidas a referéndum consultivo 'de todos los ciudadanos'. De este modo, a priori, parece que se estaría refiriendo a todo el cuerpo electoral”.

En respuesta a la posible limitación del artículo 92 de la Constitución para este fin, cabría la posibilidad de que el legislador orgánico incorporara a la Ley Orgánica 2/1980 un nuevo referéndum consultivo, de ámbito autonómico. Ocurre, no obstante, que la citada Ley está prevista por la Constitución para regular las modalidades de referéndum previstas en ella, y aquí hablamos de una figura no

\footnotetext{
19 Entre otras, SSTC 103/2008, 31/2009 y 42/2014.

20 Disposición Adicional de la LOMR: "Las disposiciones de la presente Ley no alcanzan en su regulación a las consultas populares que puedan celebrarse por los Ayuntamientos, relativas a asuntos relevantes de índole municipal, en sus respectivos territorios, de acuerdo con la legislación de Régimen Local, y a salvo, en todo caso, la competencia exclusiva del Estado para su autorización".

21 Artículo 71 LBRL: "De conformidad con la legislación del Estado y de la Comunidad Autónoma, cuando ésta tenga competencia estatutariamente atribuida para ello, los Alcaldes, previo acuerdo por mayoría absoluta del Pleno y autorización del Gobierno de la Nación, podrán someter a consulta popular aquellos asuntos de la competencia propia municipal y de carácter local que sean de especial relevancia para los intereses de los vecinos, con excepción de los relativos a la Hacienda local". La previsión de autorización previa del Gobierno parece indicar que estamos ante consultas referendarias, en seguimiento de lo dispuesto en el artículo 149.1.32 CE.
} 
contemplada constitucionalmente. Por tanto, parece apropiado que su regulación viniera dada por una ley específica. En todo caso, este nuevo texto debería salvaguardar la exigencia de autorización estatal de la convocatoria que prevé el artículo 149.1.32 de la Constitución. Además, y en tanto en cuanto desarrolla el derecho fundamental de participación política, habrá de ser ley orgánica (artículo 81.1 de la Constitución).

Lo que bajo ningún concepto sería admisible es que la regulación primaria de este referéndum autonómico viniera dada por una ley asimismo autonómica. $Y$ ello porque, como hemos expuesto, el Tribunal Constitucional ha sido tajante al señalar que la entera disciplina de la institución referendaria corresponde al Estado, sin que puedan las Comunidades asumir competencias más allá de un impreciso desarrollo normativo. Cuando aún estaba pendiente de resolverse el asunto relativo al Estatuto de Cataluña, el Parlamento catalán aprobó una Ley, la 4/2010, de consultas populares por vía de referéndum. La Ley parte del presupuesto, que más tarde el Tribunal Constitucional negó, de que el inciso final del artículo 122 del Estatuto incluye los referendos. Así, regula el uso del referéndum a nivel autonómico, con carácter consultivo, restringido a materias de competencia autonómica, y sometido a la previa autorización del Estado. El Presidente del Gobierno decidió impugnar la Ley, planteando un recurso que fue admitido por el Tribunal, lo que supuso su suspensión automática. Aún no se ha resuelto el asunto, pero en junio de 2011 el Pleno del Tribunal decidió levantar la citada suspensión. Por tanto, a día de hoy es una norma jurídica plenamente válida, y podría utilizarse como cobertura para un referéndum autonómico de carácter consultivo en Cataluña.

\subsection{Referéndum de autodeterminación}

Supongamos que el legislador orgánico aprobara finalmente la regulación de un nuevo tipo de referéndum autonómico. Más allá de las dudas ya planteadas acerca del margen que tendrían las Comunidades Autónomas para el desarrollo de tal normativa en base a los postulados de la STC 137/2015, conviene plantearse un interrogante de vital importancia: ¿ese referéndum podría tener cualquier objeto? ¿Cabría la posibilidad de que una Comunidad consultara a sus ciudadanos acerca de una eventual independencia de España?

Aquí resulta de nuevo imprescindible atender a la jurisprudencia constitucional. En la ya citada STC 103/2008, el Tribunal Constitucional se enfrentó al debate en términos muy similares a los aquí planteados. A través de la consulta promovida por el Lehendakari Ibarretxe se pretendía iniciar un procedimiento de reconsideración de la relación entre País Vasco y España, otorgando al pueblo vasco una suerte de derecho a decidir equivalente al que posee como soberana la nación española.

El Tribunal fue tajante al afirmar que una cuestión de tal índole venía a afectar al orden constitucional vigente (en concreto al artículo $2 \mathrm{CE}$ ), "en la medida en que supone la reconsideración de la identidad y unidad del sujeto soberano o, cuando menos, de la relación que únicamente la voluntad de éste puede establecer entre el Estado y las Comunidades Autónomas". De esta manera, añade el Tribunal, la vía para operar una reconsideración tal no puede ser sino la revisión del texto constitucional a través del procedimiento del artículo $168 \mathrm{CE}$.

La conclusión parece clara: una Comunidad Autónoma no podría en ningún caso plantear un referéndum de autodeterminación a sus ciudadanos. Ello implicaría 
afectación a un orden constitucional cuya reforma, si bien puede darse sin límite material alguno, tiene mecanismos de seguimiento indispensable ${ }^{22}$.

De este pronunciamiento podemos extraer un principio más amplio que aquel que niega la posibilidad de celebrar referendos autonómicos de secesión: las consultas solo pueden tener por objeto materias en las que la Comunidad de que se trate posea competencia. Esta premisa está presente, por ejemplo, en la regulación estatal básica sobre el referéndum municipal. Así, el artículo 71 de la Ley de Bases del Régimen local habla de "asuntos de la competencia propia municipal y de carácter local". Igualmente, la citada ley catalana 4/2010, de consultas populares por vía de referéndum, indica en su artículo 10 que "el objeto de las consultas populares por vía de referéndum de ámbito de Cataluña son las cuestiones políticas de especial trascendencia para la ciudadanía en el ámbito de las competencias de la Generalidad".

Hablaríamos únicamente, pues, de preguntas relativas a materias de competencia autonómica. A pesar de esta limitación, relevantes constitucionalistas han defendido una vía para poder sondear lícitamente al pueblo autonómico de que se trate acerca de una eventual puesta en marcha de un procedimiento orientado a la consecución de la secesión. La construcción descansa en la idea de que forma parte de las atribuciones de toda Comunidad Autónoma el ejercicio de la iniciativa de reforma constitucional ${ }^{23}$ (artículo 166. ${ }^{24}$, en relación con el $87.2^{25}$, ambos de la Constitución). En consecuencia, una consulta referendaria cuyo objeto fuera preguntar si los ciudadanos apoyan que su Parlamento autonómico envíe a las autoridades estatales un proyecto de reforma constitucional de sesgo secesionista, resultaría plenamente legítima.

Bajo ciertas circunstancias, esta vía resulta impecable en términos constitucionales. Así, el Parlamento autonómico no debería estar jurídicamente vinculado al parecer del cuerpo electoral, pues de lo contrario se produciría un falseamiento en la titularidad de la facultad de plantear la proposición de reforma constitucional. La consulta debería tener, pues, meros efectos consultivos. Las consecuencias de una hipotética negativa del Parlamento autonómico habría de jugar exclusivamente en el terreno político. Lo mismo ocurriría en el caso de que, si finalmente se plantea la propuesta a las Cortes Generales, éstas decidan no operar

\footnotetext{
22 En muy similares términos se expresa la STC 42/2014: "El planteamiento de concepciones que pretendan modificar el fundamento mismo del orden constitucional tiene cabida en nuestro ordenamiento, siempre que no se prepare o defienda a través de una actividad que vulnere los principios democráticos, los derechos fundamentales o el resto de los mandatos constitucionales, y el intento de su consecución efectiva se realice en el marco de los procedimientos de reforma de la Constitución, pues el respeto a esos procedimientos es, siempre y en todo caso, inexcusable".

23 Vintró (2012) considera que la expresión "ámbito de competencias" debe interpretarse "de manera que el objeto de las consultas pueda incluir, además de cuestiones sobre el elenco estatutario de materias competenciales, también preguntas relativas a las facultades de la Generalidad reconocidas por la Constitución y el Estatuto entre las que se encuentra el ejercicio de la iniciativa de reforma constitucional como se desprende de los artículos 166 y 87 del texto constitucional". Igualmente, Aguiar (en manuscrito de próxima publicación) entiende que "la posibilidad de que la Asamblea legislativa de una Comunidad Autónoma acuerde elaborar una proposición de reforma constitucional y que con carácter previo a la aprobación de su remisión a las Cortes someta tal propuesta a una consulta popular por vía de referéndum en el ámbito de la propia Comunidad Autónoma respectiva y con efectos meramente consultivos, no parece que pueda a título de principio suscitar grandes reparos de inconstitucionalidad".

${ }^{24}$ Artículo 166 CE: "La iniciativa de reforma constitucional se ejercerá en los términos previstos en los apartados 1 y 2 del artículo 87 ".

${ }^{25}$ Artículo 87.2 CE: "Las Asambleas de las Comunidades Autónomas podrán solicitar del Gobierno la adopción de un proyecto de ley o remitir a la Mesa del Congreso una proposición de ley, delegando ante dicha Cámara un máximo de tres miembros de la Asamblea encargados de su defensa".
} 
una reforma en los términos sugeridos por la Comunidad en cuestión. Salvaguardadas las facultades de ambos Parlamentos, la vía propuesta merece una opinión favorable ${ }^{26}$.

\section{Conclusiones}

Tras casi cuarenta años de funcionamiento del engranaje constitucional de 1978, con un sistema democrático plenamente asentado y unos partidos políticos fuertes, convendría reflexionar si no ha llegado el momento de introducir mecanismos de participación directa que puedan actuar como eficaces contrapesos al gran poder del que en su día se dotó al sistema representativo. De gran interés resulta, en este sentido, la propuesta de reforma constitucional planteada por el Parlamento de Asturias en $2014^{27}$. En ella se aboga por la inclusión de relevantes innovaciones en nuestro actual artículo $92 \mathrm{CE}$ : i) la posibilidad de que el referéndum consultivo sea también planteado a iniciativa de 500.000 electores; y ii) la articulación de un referéndum derogatorio al estilo del vigente en el ordenamiento italiano y de activación a propuesta asimismo de 500.000 electores.

Junto con la potenciación del instrumento referendario en el ámbito nacional, parece ineludible su regulación en el nivel autonómico. Escaso sentido tiene que en la actualidad un Ayuntamiento pueda consultar a sus vecinos acerca del ejercicio concreto de una facultad de su competencia y, sin embargo, una Comunidad Autónoma tenga vetada esta posibilidad. La cercanía al ciudadano de ambos niveles hace especialmente propicio el instituto como cauce de participación complementario de los regulares mecanismos representativos. Sería saludable, en este sentido, la inclusión del referéndum autonómico en la propia Constitución Española, aclarando qué espacio queda para su regulación por parte de las autoridades autonómicas en desarrollo de la normativa estatal, que seguirá siendo imprescindible en garantía de una cierta uniformidad en un terreno propio de ley orgánica.

De no lograrse una reforma constitucional de este signo, nada impide la existencia del referéndum autonómico. No figura tampoco en el texto constitucional referencia alguna sobre la iniciativa legislativa popular de ámbito autonómico, y ello no ha sido obstáculo para su utilización. Siempre que estas consultas queden circunscritas al ámbito de las competencias propias de cada Comunidad, no se atisba inconveniente alguno en su previsión y empleo.

Se ha argumentado aquí la poca consistencia de la doctrina del Tribunal Constitucional relativa a la necesidad de que la entera disciplina de la institución referendaria sea configurada por el Estado (doctrina que, de hecho, fue matizada más tarde por el propio Tribunal). Al igual que ocurre en el ámbito de las elecciones autonómicas, la normativa básica del Estado debe permitir su desarrollo a través de la intervención de los Parlamentos autonómicos. Recuérdese que el Estado conservará, en todo caso, una "bala de plata" para bloquear consultas que considere nocivas para el interés general: la necesaria autorización de la convocatoria, prevista en el artículo 149.1.32 CE.

\footnotetext{
${ }^{26}$ No es de esta opinión Castellà (2013: 198-199), quien considera que "una interpretación tan amplia del alcance del término 'competencia' (...) vacía completamente el significado preciso que la doctrina iuspublicista, en España y en los Estados políticamente compuestos, ha atribuido a la competencia como conjunto de facultades jurídicas que ostenta un ente público sobre una materia determinada". El autor entiende, asimismo, que la exclusión expresa que realiza la Constitución de la iniciativa popular en la reforma constitucional impediría poder emplear el referéndum autonómico para este fin.

27 Puede consultarse en Boletín Oficial de la Junta General del Principado de Asturias de 25 de septiembre de 2014.
} 
Si finalmente se alcanzara la creación de una ley orgánica reguladora de los referendos de ámbito autonómico, ello no permitiría deducir de manera incontrovertida que una Comunidad Autónoma pudiera emplearla para plantear un referéndum de autodeterminación. Como se ha expuesto, el Tribunal Constitucional ha sido rotundo al indicar que este tipo de consultas afectan a un orden constituido cuya reforma, no proscrita, debe realizarse por los canales constitucionalmente habilitados para ello. Abierto queda el debate sobre si una consulta centrada en el planteamiento a las Cortes Generales de una iniciativa de reforma constitucional de naturaleza secesionista puede o no encontrar encaje en el marco señalado: el imprescindible respeto al ámbito competencial autonómico.

\section{Bibliografía}

AGUADO RENEDO, C. (2011), "Referéndum autonómico y jurisprudencia constitucional", Teoría y Realidad Constitucional, núm. 28, pp. 541-554.

AGUIAR DE LUQUE, L. (2000), "Democracia directa e instituciones de democracia directa en el ordenamiento constitucional español". En: LÓPEZ GUERRA, L., TRUJILLO, G., y GONZÁLEZ TREVIJANO, P., La experiencia constitucional (1978-2000), Madrid, Centro de Estudios Políticos y Constitucionales, pp. 67-96.

AGUIAR DE LUQUE, L. (2017), "Referéndum y Estado Autonómico: una reflexión desde la jurisprudencia constitucional". En: obra colectiva de próxima publicación.

ALÁEZ CORRAL, B. (2015), "Constitucionalizar la secesión para armonizar la legalidad constitucional y el principio democrático en estados territorialmente descentralizados como España", Revista d'estudis autonòmics i federals, núm. 22, pp. 136-183.

ALZAGA, Ó. (1980), Comentarios a la Constitución, Ediciones del Foro, Madrid.

ARAGÓN REYES, M. (1989), Constitución y democracia, Tecnos, Madrid.

CARRASCO DURÁN, M. (2013), "Referéndum versus consulta", Revista de Estudios Políticos, núm. 160, pp. 13-41.

CASTELLÀ ANDREU, J.M. (2013), "Democracia, reforma constitucional y referéndum de autodeterminación en Cataluña". En: ÁLVAREZ CONDE, E. y SOUTO GALVÁN, C., El Estado autonómico en la perspectiva de 2020, Madrid, Universidad Rey Juan Carlos, Instituto de Derecho Público, pp. 171-212.

CASTELLÀ ANDREU, J.M (2016), "El referéndum en la Constitución: ¿es necesario un replanteamiento de la institución?". En: CASCAJO CASTRO, J.L, y MARTÍN DE LA VEGA, A., Participación, representación y democracia - XII Congreso de la Asociación de Constitucionalistas de España, Valencia, Tirant Lo Blanch, pp. 235-266.

CUESTA LÓPEZ, V. (2008), Participación directa e iniciativa legislativa del ciudadano en democracia constitucional, Civitas, Pamplona.

GARCÍA-ESCUDERO MÁRQUEZ, P. (2008), "El procedimiento agravado de reforma de la Constitución de 1978”, Revista de Derecho Político, núms. 71-72, pp. 177-193.

GARRORENA MORALES, Á. (1991), El Estado español como Estado social y democrático de Derecho, Tecnos, Madrid.

MARTÍN NUÑEZ, E. (2012), "El referéndum y las consultas populares en las Comunidades Autónomas y municipios", Revista Vasca de Administración Pública, núm. 94, pp. 95-131.

REQUEJO RODRÍGUEZ, P. (2014), "El referéndum consultivo en España: reflexiones críticas y algunas propuestas de futuro", Estudios de Deusto, núm. 62/1, pp. 261-284.

RODRÍGUEZ ZAPATERO, J.L. (1986), "El referéndum consultivo del artículo 92 de la Constitución Española de 1978: un análisis crítico", Diario La Ley, núm. 7005, pp. 1156-1166. 
TAJADURA TEJADA, J. (2009), "Referéndum en el País Vasco. (Comentario a la STC 103/2008, de 11 de septiembre)", Teoría y Realidad Constitucional, núm. 23, pp. 363-385.

VINTRÓ CASTELLS, J. (2012), "Legalidad y consulta soberanista en Cataluña", Blog del Instituto de Derecho Público. Disponible en la siguiente dirección electrónica: http://idpbarcelona.net/legalidad-y-consulta-soberanista-encataluna/ (fecha de consulta: 19 de diciembre de 2016).

VÍRGALA FORURIA, E. (2013), "Crisis de la representación y democracia directa en España", Revista Parlamentaria de la Asamblea de Madrid, núm. 29, pp. 11-26. 